\title{
Non-essential Metals in Chemical Biology
}

\author{
Paul J. Dyson*
}

\begin{abstract}
Metal ions and compounds are essential to life and many people routinely take them as food supplements in the form of vitamin and mineral pills. Most non-essential metals are considered to be toxic, nevertheless, many are widely used in imaging, diagnostics and medicine. This short review provides an overview from selected examples of the on-going research within my laboratory that uses metal compounds to either understand biological processes or that exhibit therapeutic properties overcoming the limitations of existing chemotherapies.
\end{abstract}

Keywords: Bioinorganic chemistry · Bioorganometallic chemistry · Enzyme inhibition · Protein crystallography

While life depends on essential metal ions to fulfil a wide and diverse range of functions, ${ }^{[1]}$ modern medicine utilizes a number of non-essential metal ions in a diverse range of applications including diagnostics, imaging and therapeutic applications. ${ }^{[2]}$ Other non-essential metal compounds have been exploited in biochemistry and molecular biology for many years, such as ruthenium red that has been used as a tool to study specific cellular mechanisms but is limited as it interacts with a large number of proteins including ion channels. ${ }^{[3]}$ Consequently we evaluated a series of fluorescent ruthenium tris(bipyridine) complexes in which the bipyridine ligand is derivatised with substituents. ${ }^{[4]}$ The complexes were found to penetrate cells and accumulate in different locations depending upon the functional group attached to the bipyridine ligand. The most lipophilic complex, [Ru(4,4'-diethylamino-2,2'bipyridine) $)_{3}$, was found to adhere to the plasma membrane and could prove to be a useful staining agent in certain applications (Fig. 1). The nature of the ligands attached to the ruthenium centre are critical in determining the localisation of the compound in cells and a ruthenium polypyridyl

${ }^{*}$ Correspondence: Prof. Dr. P. J. Dyson Institut des Sciences et Ingénierie Chimiques Ecole Polytechnique Fédérale de Lausanne (EPFL) $\mathrm{CH}-1015$ Lausanne

Tel.: +41216939854

Fax: +41216939780

E-mail paul.dyson@epfl.ch

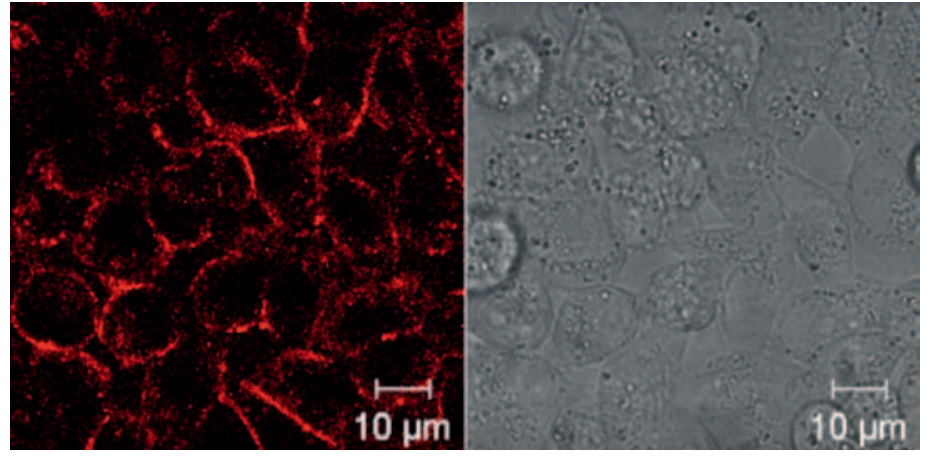

Fig. 1. Confocal fluorescence microscopy showing accumulation of $\left[\mathrm{Ru}\left(4,4^{\prime}\right.\right.$ '-diethylamino2,2'-bipyridine) ${ }_{3}$ ] at the plasma membrane. The image on the left shows the fluorescence of the compound (red) and on the right the transmitted light.

complex was found to accumulate in the cell nucleus and can even be used to directly image the DNA structure in vitro. ${ }^{[5]}$ Nevertheless, the metal does exert some influence, as shown from a study in which we derivatised a ruthenium(II) complex with an organic ligand that overcomes multidrug resistance in certain tumours. Compared to the free organic molecule, uptake of the ruthenium complex into cells was considerably faster as is accumulation in the cell nucleus. ${ }^{[6]}$ The ruthenium centre appears to be responsible for these effects - with initial uptake enhanced by the neutral ruthenium complex which is then hydrolysed inside the cell and becomes positively charged, facilitating accumulation in the nucleus.

While the fluorescent properties of metal compounds emanating from the ligands attached to them are useful, most non-essential elements have unique, intrinsic properties such as distinct isotopic patterns and spectroscopic handles that vastly expand their utility in a biological environment. For example, metals not present in living systems can be detected and distinguished from background elements by inductively coupled plasma mass spectrometry (ICP MS) at picomolar concentrations in cells. ${ }^{[7]}$ We recently used ICP MS to establish the location of cisplatin and two ruthenium drugs in clinical trials in ovarian cancer cells. ${ }^{[8]}$ Ovarian cancer cells both susceptible and resistant to cisplatin were used in the study and differences in cellular uptake, localization in the cell nucleus and mitochondria, and also their expulsion from the cells was established providing valuable information on drug resistance.

It is even possible to determine the precise biomolecular targets of these metal drugs by separation of the protein fractions by gel electrophoresis and subsequent analysis of the gels by laser ablation ICP MS, which identifies the specific proteins to which the metal binds - assuming covalent binding - following extraction of the metal-containing protein band/spot and characterisation by conventional proteomics methods. ${ }^{[9]}$ Other chromatographic approaches have also been employed to achieve essentially the same task. ${ }^{[10]}$ Moreover, since most metal compounds bind to their biomolecular targets via covalent bonds, determination of the precise binding site(s) is possible due to the unique and distinctive isotope patterns of metals, using both bottom-up ${ }^{[11]}$ and top-down ${ }^{[12]}$ approaches to break the biomolecule into fragments allowing the part where the metal binds to be identified. Consequently, metal compounds represent ideal labels that can be detected at very low levels using various analytical techniques on different scales, i.e. from general localization within the cell to the interaction with specific biomolecules including DNA, RNA and proteins, and ultimately to the exact binding site on the biomolecular 


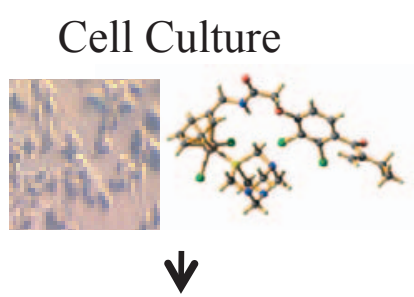

Fractionation and electrophoresis
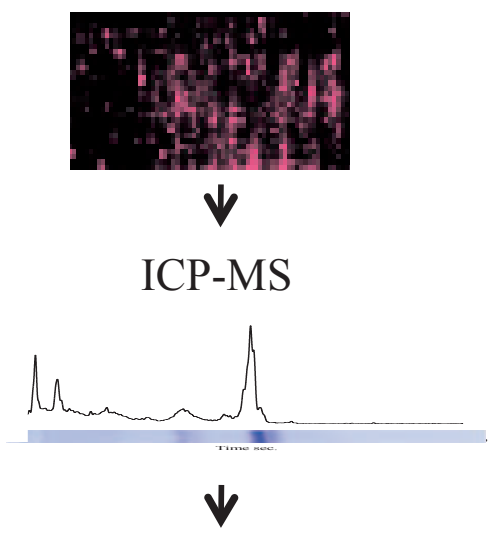

Excision and processing

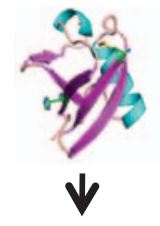

Protein Digestion and peptide extraction

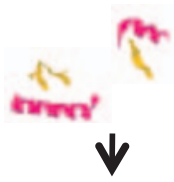

Peptide sequencing by MS-MS

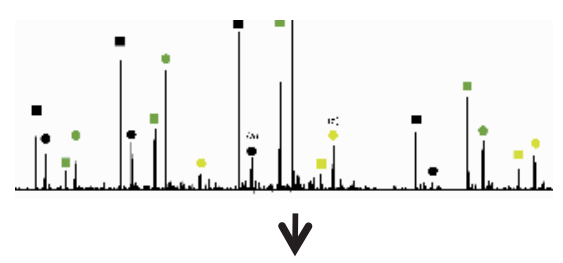

\section{Protein identification/binding site localization}

MQIFVKTLTG KTITLEVEPS DTIENVKAKI QDKEGIPPDQ QRLIFAGKQL EDGRTLSDYN IQKESTLHLV LRLRGG
Fig. 2. Methodology combining cell culture, gel electrophoresis, laser ablation inductively coupled plasma mass spectrometry and proteomics techniques that allows the proteins that interact with metal compounds to be identified. In the case of covalent modification, characteristic of metal-drugs, the binding sites can be identified. target. Fig. 2 provides an overview of the approach that we have developed to delineate the fate of metal compounds, typically putative drug candidates, in cell culture. It should be noted that the same methodology could be used to analyse biopsy samples such a tumour tissue from a patient following a course of chemotherapy.

Our studies have focussed on platinum and ruthenium compounds in relation to their anticancer activity. Platinum com- pounds are widely used in the clinic to treat a broad range of cancers ${ }^{[13]}$ and two ruthenium drugs are currently undergoing clinical trials. ${ }^{[14]}$ Ruthenium compounds appear to be better tolerated by the body, consequently having reduced side-effects, cautiously attributed to the similarity between ruthenium and iron - the body being well equipped to transport and store the latter. ${ }^{[15]}$ Moreover, while DNA is a relevant target for metal drugs, interactions with en- zymes and proteins are abundant and critical, and of high relevance for ruthenium compounds. In our own research we have developed a series of organoruthenium compounds, termed RAPTA, that display selective antimetastatic[16] and antiangiogenic activity (Fig. 3).[17]

Their mode of action is very different to that of cisplatin and other cytotoxic platinum agents and while both classes of compound reach the cell nucleus the platinum compounds bind to many different DNA and histone sites within the nucleosome ${ }^{[18]}$ whereas the RAPTA compounds show a strong preference for binding to the histone protein core. ${ }^{[19]}$ This difference may be appreciated from the $c a .200 \mathrm{KDa}$ structure of the nucleosome core particle soaked with the various drugs - Fig. 4 shows binding of $\left[\mathrm{Ru}\left(\eta^{6}-p\right.\right.$-cymene $) \mathrm{Cl}_{2}$ (pta)] (RAPTA-C) to the nucleosome core particle exclusively at the histone core.

The mechanism of action of RAPTA-C and other RAPTA compounds has been partly elucidated from a series of in vitro and in vivo experiments. ${ }^{[20]}$ Treatment with RAPTA-C triggers $\mathrm{G}_{2} / \mathrm{M}$ phase arrest and apoptosis, associated with increased levels of p21 and p53 and reduced amounts of cyclin $\mathrm{E}$, the release of cytochrome $c$ and caspase- 9 activation. However, the origin of the selectivity of the compound towards highly invasive and metastatic tumours is poorly understood. [21] Nevertheless, improvements on the efficacy of these compounds have been attempted. For example, modification with ethacrynic acid, a glutathione transferase inhibitor, markedly alters the anticancer properties of these compounds. ${ }^{[22]}$ Since the RAPTA family of compounds are investigational drug compounds we also modified cisplatin with ethacrynic acid for comparison (Fig. 3). [23] It should be noted that in certain cancers, including solid metastases, there is a correlation between over-expression of glutathione transferases (GSTs), that catalyse the nucleophilic attack by reduced glutathione on cancer chemotherapeutic agents, which is part of a defence strategy to remove glutathione conjugates from the cell.[24] The structure of the most effective ruthenium-ethacrynate derivative, viz. $\quad\left[\mathrm{Ru}\left(\eta^{6}\right.\right.$-phenylethacrynate $) \mathrm{Cl}_{2}$ (pta) co-crystallised with GST P1-1 (the human form of the enzyme associated with drug resistance) is shown in Fig. 5. ${ }^{[22 b]}$

Remarkably, over time the RAPTApart of the structure $\mathrm{Ru}$-centre, arene and phosphine co-ligands) is cleaved from the ethacrynic acid group, the former being expelled from the GST and the latter remaining behind, inhibiting the enzyme. This scission-elimination process was established by several different techniques and appears to explain the overall mode of action of the compound, involving apoptosis 


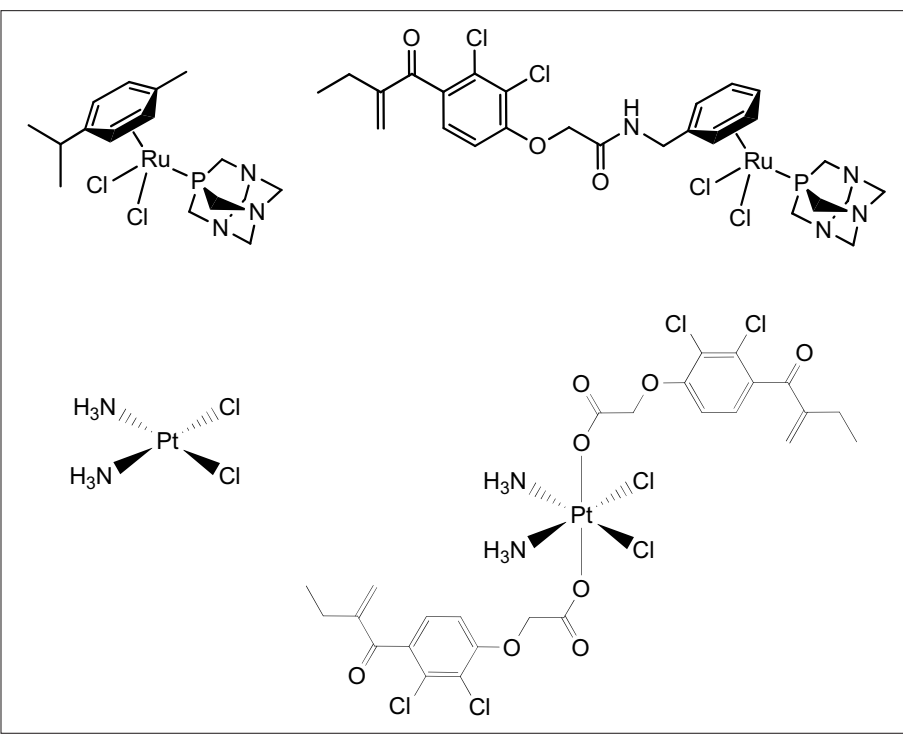

Fig. 3. Structure of RAPTA-C (top left), $\left[R u\left(\eta^{6}-\right.\right.$ phenylethacrynate) $\mathrm{Cl}_{2}$ (pta)] (top right) cisplatin (bottom left) the Pt(Iv) prodrug, ethacraplatin (bottom right).

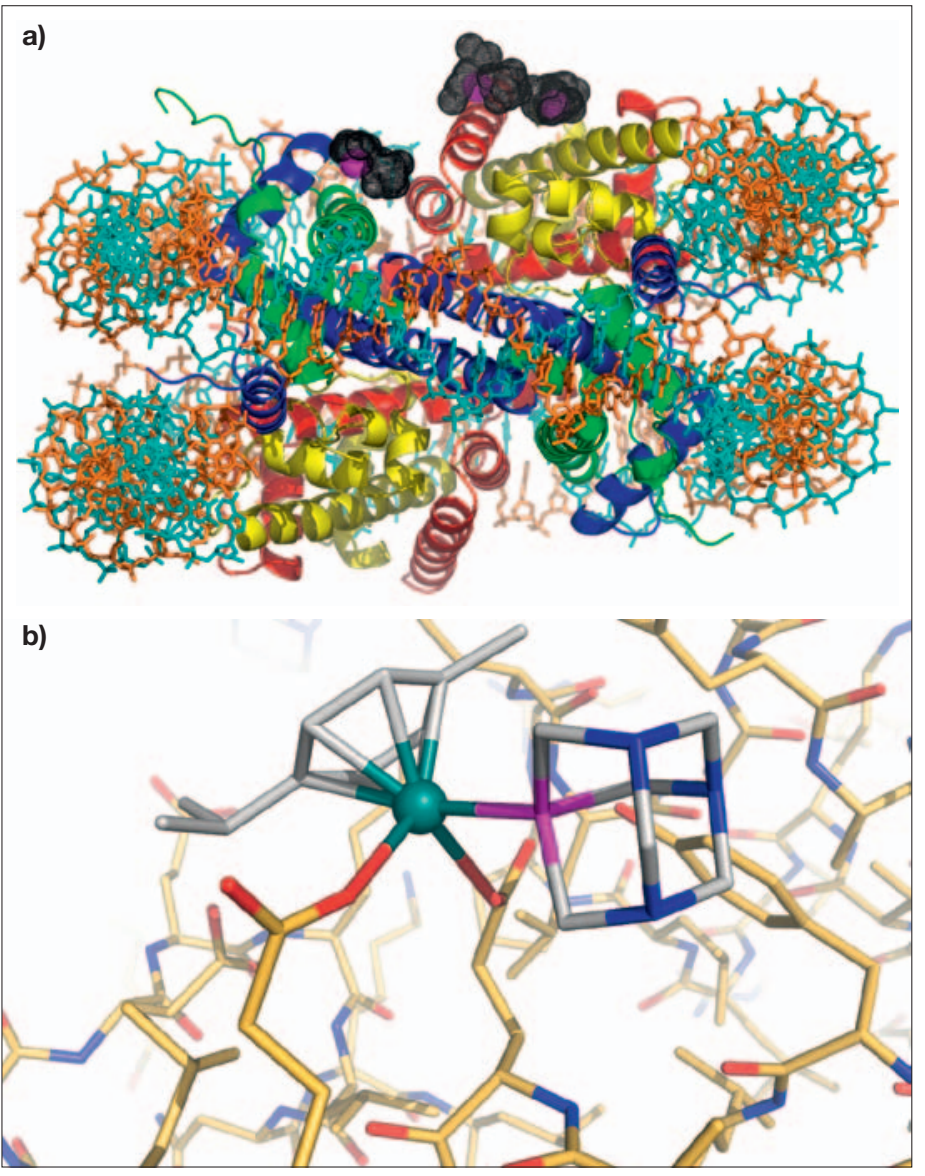

Fig. 4. Location of RAPTA-C binding sites in the nucleosome on the histone core viewed down the pseudo-twofold axis of symmetry of the particle. The two 145 nucleotide DNA strands are cyan and orange and the RAPTA-C Ru-ion is shown in magenta and RAPTA-C ligands in black (a). The main histone protein adduct formed with RAPTA-C, via substitution of the two chloride ligands, with two glutamate residues (b).

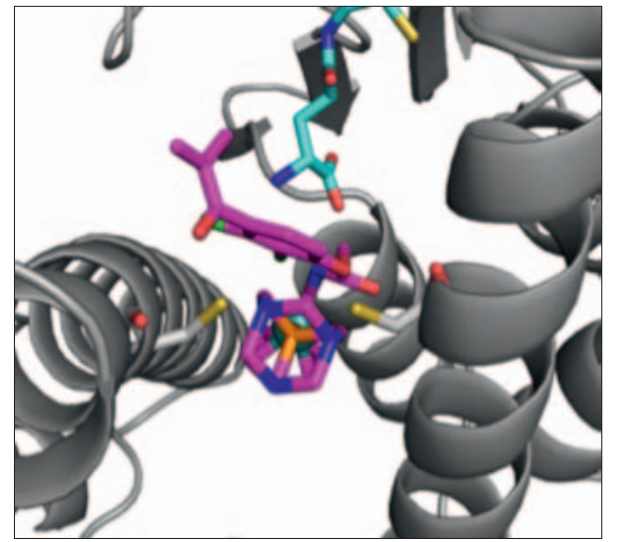

via a two-phase process. An initial surge of programmed cell death is followed by a more significant wave after several days. ${ }^{[25]}$ Initial binding of the compound to GST P1-1 results in activation of the JNK apoptosis pathway. Subsequent release of the ruthenium fragment induces cytotoxicity via a multi-mechanism pathway and also triggers cell protection mechanisms, e.g. expression of heat shock protein 70 (possibly in response to inhibition of heat shock protein 90), that provides selectivity towards apoptosis-resistant cancer cells, thus protecting healthy cells. The structure of the $\mathrm{Pt}(\mathrm{IV})$-ethacrynate compound, termed ethacraplatin, bound to GST P1-1 has also been determined with the Pt ion reduced from $\mathrm{Pt}(\mathrm{IV})$ to $\mathrm{Pt}(\mathrm{II})$, binding to the two cystine101 residues at the dimer interface with the two ethacrynic acid moieties released from the metal bound at both H-sites. ${ }^{[26] ~ A ~ d e t a i l e d ~ e x p e r i m e n t a l ~ a n d ~}$ theoretical mechanistic study of the binding process suggests that the compound initially migrates to the dimer interface, and subsequently is reduced and cleaved permitting the diffusion of the EA fragments to the $\mathrm{H}$-sites in the enzyme. Again, it would appear that ultimately the $\mathrm{Pt}$ (II) ion is released, allowing it to exert its cytotoxic effect without being deactivated by the ethacrynic acid inhibited GST enzyme.

In summary, drug resistance is a recurring problem in anticancer chemotherapy and is a complex problem involving many different cellular deactivation pathways Current approaches to tackle this problem in the clinic tend to be based on the application of combination therapies involving cocktails of drugs, radiotherapy and surgery. However, due to different rates of drug accumulation, compounds in which the 'anticancer component' is linked to the inhibitor such as those described here could prove advantageous in a clinical setting. In addition, there are very few selective drugs currently available for the treatment of metastasis, the main cause of mortality in patients diagnosed with cancer, and the ruthenium-based compounds described here show promise in this respect, even though the reason for their selectivity is only partly understood. We have prepared and studied other compounds related to those mentioned above, considering a number of different targeted and targeting approaches.[27] Moreover, since metals such as platinum, ruthenium, and many others are not naturally present in living systems, and have powerful analytical handles, their biodistribution, cellular localisation, biomolecular targets and even specific binding sites can be established. Consequently, metal compounds are not only used in clinical applications but for many years have been used to illuminate various biological functions and 
are likely to be increasingly used as tools in chemical biology.

\section{Acknowledgements}

My thanks go to all my co-workers and collaborators past and present whose names appear in the references. Thanks also to all the agencies and foundations that have funded my research including the NCCR in Chemical Biology.

Received: August 28, 2011

[1] See for example most textbooks on 'bioinorganic chemistry' for information on the role of trace metals in living systems.

[2] a) Z. Guo, P. J. Sadler, Angew. Chem. Int. Ed. 1999, 38, 1512; b) J. C. Dabrowiak, 'Metals in Medicine', Wiley, 2009.

[3] G. Hajnóczky, G. Csordás, S. Das, C. GarciaPerez, M. Saotome, S. Sinha Roy, M. Yi, Cell Calcium 2006, 40, 553.

[4] O. Zava, S. M. Zakeeruddin, C. Danelon, H. Vogel, M. Grätzel, P. J. Dyson, ChemBioChem 2009, 10, 1796.

[5] M. R. Gill, J. Garcia-Lara, S. J. Foster, C. Smythe, G. Battaglia, J. A. Thomas, Nat. Chem. 2009, 1,662 .

[6] C. A. Vock, W. H. Ang, C. Scolaro, A. D Phillips, L. Lagopoulos, L. Juillerat-Jeanneret, G. Sava, R. Scopelliti, P. J. Dyson, J. Med. Chem. 2007, 50, 2166.

[7] A. E. Egger, C. Rappel, M. A. Jakupec, C. G. Hartinger, P. Heffeter, B. K. Keppler, J. Anal. At. Spectrom. 2009, 24, 51.

[8] M. Groessl, O. Zava, P. J. Dyson, Metallomics 2011, 3, 591.

[9] C.S. Allardyce, P. J. Dyson, F. R. Abou-Shakra, H. Birtwhistle, J. Coffey, Chem. Commun. 2001, 2708; b) I. Khalaila, A. Bergamo, F. Bussy, G. Sava, P. J. Dyson, Int. J. Oncol. 2006, 29, 261.

[10] a) J. Will, A. Kyas, W. S. Sheldrick, D. Wolters, J. Biol. Inorg. Chem. 2007, 12, 883; b) J. Will, W. S. Sheldrick, D. Wolters, J. Biol. Inorg. Chem. 2008, 13, 421 .

[11] I. Khalaila, C. S. Allardyce, C. Verma, P. J. Dyson, ChemBioChem 2005, 6, 1788.

[12] For example see, a) C. G. Hartinger, Y. O
Tsybin, J. Fuchser, P. J. Dyson, Inorg. Chem 2008, 47, 17; b) A. E. Egger, C. G. Hartinger, H. B. Hamidane, Y. O. Tsybin, B. K. Keppler, P. J. Dyson, Inorg. Chem. 2008, 47, 10626.

[13] L. Kelland, Nat. Rev. Cancer 2007, 7, 573.

[14] C. G. Hartinger, S. Zorbas-Seifried, M. A. Jakupec, B. Kynast, H. Zorbas, B. K. Keppler, J. Inorg. Biochem. 2006, 100, 891.

[15] G. Vallerio Luis Jr., Toxicology Mechanisms and Methods 2007, 17, 497.

[16] C. Scolaro, A. Bergamo, L. Brescacin, R. Delfino, M. Cocchietto, G. Laurenczy, T. J. Geldbach, G. Sava, P. J. Dyson, J. Med. Chem. 2005, 48, 4161.

[17] P. Nowak-Sliwinska, J. R. van Beijnum, A Casini, A. Nazarov, G. Wagnières, H. van den Bergh, P. J. Dyson, A. W. Griffioen, J. Med. Chem. 2011, 54, 3895 .

[18] B. Wu, P. Droge, C. A. Davey, Nature Chem. Biol. 2008, 4, 110.

[19] B. Wu, M. S. Ong, M. Groessl, Z. Adhireksan, C. G. Hartinger, P. J. Dyson, C. A. Davey, Chem. Eur. J. 2011, 17, 3562.

[20] S. Chatterjee, S. Kundu, A. Bhattacharyya, C. G. Hartinger, P. J. Dyson, J. Biol. Inorg. Chem. 2008, 13, 1149.

[21] A. Bergamo, A. Masi, P. J. Dyson, G. Sava, Int J. Oncol. 2008, 33, 1281.

[22] a) W. H. Ang, A. De Luca, C. Chapuis-Bernasconi, L. Juillerat-Jeanneret, M. Lo Bello, P. J. Dyson, ChemMedChem. 2007, 2, 1799; b) W H. Ang, L. J. Parker, A. De Luca, L. JuilleratJeanneret, C. J. Morton, M. Lo Bello, M. W. Parker, P. J. Dyson, Angew. Chem. Int. Ed. 2009, 48, 3854.

[23] W. H. Ang, I. Khalaila, C. S. Allardyce, L. Juillerat-Jeanneret, P. J. Dyson, J. Am. Chem. Soc. 2005, 127, 1382.

[24] J. D. Hayes, J. U. Flanagan, I. R. Jowsey, Ann. Rev. Pharmacol. \& Toxicol. 2005, 45, 51

[25] S. Chatterjee, I. Biondi, P. J. Dyson, A. Bhattacharyya, J. Biol. Inorg. Chem. 2011, 16, 715.

[26] L. J. Parker, L. C. Italiano, C. J. Morton, N. C. Hancock, D. B. Ascher, J. B. Aitken, H. H. Harris, P. Campomanes, U. Rothlisberger, A. De Luca, M. Lo Bello, W.-H. Ang, P. J. Dyson, M. W. Parker, Chem. Eur. J. 2011, 17, 7806.

[27] For example see C. G. Hartinger, P. J. Dyson, Chem. Soc. Rev. 2009, 38, 391. 